\title{
Problems of environmental pollution with heavy metals in the Russian Federation
}

\author{
Alexey Vertinsky, ${ }^{1, *}$ \\ ${ }^{1}$ Irkutsk National Research Technical University, 83, Lermontov str., 664074, Irkutsk, Russia,
}

\begin{abstract}
The causes and sources of pollution of the natural environment with heavy metals are analyzed in the study. Basic information on indicators of environmental pollution with toxic metals was presented. When assessing the state of the natural environment, the author emphasizes the need to take into account that the intake of heavy metals is caused by both natural sources and anthropogenic impact. The study provides a review of scientific sources devoted to analytical methods for determining the content of heavy metals in biological media. Within the framework of the study, the author substantiated the conclusion that it is necessary to modernize methods for determining the content of heavy metals in biological media, given that it is possible to assess the level of the content and the adverse effects of heavy metals on the human body only with accurate quantitative indicators of the background content of elements in biological media. In addition, characteristics of the microelement composition of the environment for the region under study are subject to mandatory registration. The author emphasizes the need to develop methodological approaches and establish the background regional levels of metal content in biological media.
\end{abstract}

\section{Introduction}

Metals with a density greater than $5 \mathrm{~g} / \mathrm{cm}^{3}$ are classified as heavy. Heavy metals are found naturally in rocks, soil, plants and animals in the form of minerals, water-soluble ions, salts and gases. These metals can also bind with organic and inorganic molecules, or bind to suspended finest particles in the atmosphere. Heavy metals never disappear in the natural flux of elements, but can change the chemical form in which they occur.

Heavy metals are released into the atmosphere with emissions or wastewater from three main sources: fossil fuel combustion, non-ferrous metal production and waste incineration. However, heavy metals also enter the atmosphere and water bodies through natural processes such as volcanic eruptions.

In terms of environmental protection, the most problematic heavy metals are mercury $(\mathrm{Hg})$, lead $(\mathrm{Pb})$ and cadmium $(\mathrm{Cd})$. Besides the fact that heavy metals are toxic to living organisms, many of them, such as copper $(\mathrm{Cu})$, zinc $(\mathrm{Zn})$ and iron $(\mathrm{Fe})$, are also essential trace elements for plants and animals. Some metals are found in particularly toxic forms, even in relatively small quantities, and pose a threat to human and animal health.

\footnotetext{
${ }^{*}$ Corresponding author: vertin@bk.ru
} 
The urgency of the problem of environmental pollution with heavy metals is explained, first of all, by the wide spectrum of their action on the human body. Heavy metals affect almost all systems of the body, providing toxic, allergic, carcinogenic, gonadotropic effects. As already noted, some inorganic ions are absolutely essential for normal metabolism, such as sodium, potassium, zinc, selenium, and iodine. Others (mercury, cadmium, lead) do not perform any functions and, on the contrary, have a toxic effect when accumulated in high concentrations.

The object of the research is the impact of heavy metals on the human body.

The subject of the research is scientific literature on the problems of assessing the impact of heavy metals on the human body.

The aim of the research is to study the results of domestic and foreign studies in the field of assessing the impact of heavy metals on the human body.

Research objectives: 1) characterization of sources and causes of pollution of the environment with heavy metals; 2) study of the toxic effects of metal compounds on the human body; 3 ) a review of scientific literature devoted to the analysis of methods for detecting heavy metals in biological media.

\section{Sources and causes of environmental pollution with heavy metals}

The most powerful sources of harmful emissions containing heavy metals are metallurgical enterprises specializing in the smelting and processing of non-ferrous metals, for example, the concentration of lead, cadmium and other metals increases hundreds of times in the areas adjacent to such enterprises, while the average area of influence of such industrial production is up to $1000 \mathrm{~km}^{2}$ [1].

Energy providers are also emitters of huge amounts of heavy metal waste.

Another source of heavy metal pollution is the exhaust gases of cars, with which a significant amount of lead gets into the environment and soil. Road traffic pollution is one of the most dangerous, it affects the content of heavy metals in the soil not only near cities, but also wherever transport routes pass.

Some ameliorants, for example, some soil structure formers, instead of improving arable land and stimulating plant growth, enrich the soil with lead, copper, bismuth, etc.

Thus, when assessing the state of the natural environment, it is necessary to take into account that the intake of heavy metals is caused by both natural sources and anthropogenic impact. Air pollution occurs mainly during the combustion of coal and other fossil fuels, in the smelting of iron and non-ferrous metals. Some trace elements, especially $\mathrm{Se}, \mathrm{Au}, \mathrm{Pb}$, $\mathrm{Sn}, \mathrm{Cd}, \mathrm{Bi}$, and $\mathrm{Te}$, can be more than 1000 times their natural concentration in air. In general, elements that form volatile compounds or are part of fine particles during coal combustion and other industrial processes can be more easily released into the atmosphere. Natural sources include aeolian dust, volcanic eruptions, evaporation from the surface of the water, and some others. Atmospheric deposition of trace elements, mainly heavy metals, are involved in the pollution of all other components of the biosphere - water, soil and vegetation [2].

\section{The influence of heavy metals on the human body}

It is important to emphasize that the toxicity of inorganic ions depends on many factors, including age, sex, physiological state of the body, the presence of concomitant diseases, as well as the route of entry and dose. Thus, children are at a greater risk of lead poisoning than adults, which is associated with more intense absorption of this heavy metal in the 
intestines and greater vulnerability of the nervous system in childhood. Elemental mercury does not have any toxic effect when it enters the gastrointestinal tract or intact skin, but it can cause multiple organ failure in the case of inhalation.

The main sources of entry of heavy metals and trace elements are food and water, inhaled air, and, in some cases, drugs.

Most often, cases of poisoning with heavy metals and microelements are recorded at work. One of the most striking manifestations of the toxic effects of metal compounds on the body is the so-called metal fever. This flu-like condition occurs as a result of acute upper respiratory tract exposure to heavy metal oxide vapors and is most commonly seen in metal mining and processing workers. The most common cause of "metal fever" is poisoning with oxides of zinc, magnesium, cobalt and copper.

Nowadays, an extensive scientific base has been formed on the symptomatology of clinical manifestations under the influence of heavy metals, and the factors of ecologically caused diseases of the population are presented. The effects of heavy metals on the human body have been studied in detail in numerous studies. These consequences are different. Central and peripheral nervous system damage is a common symptom of aluminum, arsenic, lead, mercury and copper poisoning. A number of scientific works have studied in detail the pathology of the nervous system in acute oral poisoning with thallium salts [3]. It is pertinent to note that few clinical cases of thallium poisoning are described in the world literature [4,5-8]. At present, based on single precedents, it is difficult to form a unified idea of the damage features, since patients are not comparable in age, the route of entry of the poison into the body, the timing and severity of poisoning, the level of thallium in biological media. In addition, several systems are involved in the pathological process, early symptoms are nonspecific, and characteristic signs appear late [9].

The suppression of the hematopoietic function is observed in case of poisoning with arsenic and lead, the excretory function - with arsenic, cadmium, chromium, selenium, lead, mercury. Damage to the mucous membranes of the gastrointestinal tract is typical in case of alimentary poisoning with cobalt, copper, iron, zinc and selenium, lung tissue damage - in case of inhalation poisoning with compounds of nickel, aluminum, manganese and mercury $[10,11-13]$.

Thus, the active production of chemical products that enter the natural environment is harmful to the human body. As a result, the immunobiological reactivity of urban residents, including the child population, changes. A large number of studies have described the disorders of the main regulatory systems of the body as a result of exposure to heavy metals. This contributes to a massive increase in morbidity, genetic disorders and other changes, which in scientific research are called ecological pathology [14,15].

Despite the large number of scientific studies in this area, the most difficult issues to date are the issues of clinical and laboratory diagnostics of diseases caused by exposure to heavy metals associated with the general symptoms of many diseases. In addition, in a number of dissertation studies, the need to improve the methods of identification and quantitative determination of metals in the study of objects of biological origin is noted [16].

\section{Review of scientific literature analyzing methods for the detection of heavy metals in biological media}

The allocation of this issue within the framework of the research topic is caused by a number of circumstances. First of all, by the need to develop methods for the analysis of biological materials, which would differ in their availability in terms of time and financial costs, as well as efficiency - allowing the most probable determination of quantitative indicators of the background content elements in biological media. It should be noted that 
the clinical picture of heavy metal intoxication does not have any specific signs and often proceeds as multiple organ failure. For this reason, the main diagnostic method is the analysis of the concentrations of toxic metals in various biological media.

In the context of the study, it is advisable to highlight several problems that occur in the practice of developing control of the content of toxic metals in biological media. Control allows preventing the negative impact of environmental factors associated with environmental pollution.

The first problem is associated with an objective assessment of the actual pollution of environmental objects. The assessment has a close relationship with the health of people inhabiting the territory of large industrial complexes [17,18]. As part of the analysis of studies devoted to a comprehensive assessment of the state of the environment, it is possible to note the insufficient study of the issues of human interaction with the environment in the ecological system "man-dose", where a complex of factors of anthropogenic nature affects a person [19,20].

As already emphasized, the most powerful sources of harmful emissions containing heavy metals are: 1) metallurgical enterprises specializing in the smelting and processing of non-ferrous metals; 2) energy enterprises; 3) road transport. As a result, the environmental situation is very difficult in those regions where these enterprises are located. And such factors as the movement of surface and groundwater, wind flow, contribute to the fact that chemical compounds that daily enter the environment migrate and redistribute over considerable distances [21]. All this makes it necessary to determine the reference limits for the content of chemical elements in the human body in relation to the population living in industrial regions with a difficult ecological situation.

In this regard, it should be noted that the environmental safety assessment should be based, among other things, on the indicators of the health status of the population of industrially developed regions [22,23]. So, for example, the ratio of the content of heavy metals in hair was the basis for a new method for predicting the impact of atmospheric pollution on health [24].

In this regard, the modernization of the methodological support of diagnostic studies in a situation of negative (toxic) impact of environmental factors of low intensity on the human body is of priority importance. Compounds of heavy metals entering the human body by various routes (inhalation, oral, parenteral, as well as through the skin and mucous membranes) accumulate in various tissues, causing toxic effects over time. As already emphasized, it is difficult to clinically identify such an effect and is not always possible [25-27]. Usually they are excreted very slowly, through the kidneys, liver, salivary and sweat glands, mucous membranes, which is accompanied by damage to these organs. In this case, an informative diagnostic indicator is the study of the content of chemical elements in biological media [28,29].

Nowadays, a number of scientists are working to improve the methodology for providing diagnostic studies to determine the concentration of heavy metals and trace elements in biological media. In particular, in modern practice of studying biological objects, spectrometric methods are widely used, which have positively proven themselves due to the possibility of determining several elements in one sample. In addition, the advantages of this method are high selectivity and sufficient sensitivity [30-32].

Domestic studies devoted to the analytical method of gas chromatography of trace amounts of metals have been covered in print since 1970 [33-35]. Since the time of the first interfacing of a gas chromatograph and a mass spectrometer in 1957 [36], this method has undergone major changes and has been significantly improved. The GC/MS method allows efficiently analyzing non-polar and low-polar substances with sufficient volatility. Currently, the capabilities of the GC/MS method have been significantly expanded with the advent of two-dimensional gas chromatography (GC $\times \mathrm{GC} / \mathrm{MS})$ [37]. 
In modern analytical practice, the following methods are used for determining the content of heavy metals in biological media: atomic absorption spectrometry [38,39-41] and inductively coupled plasma mass spectrometry (ICP-MS) [41-43]. The ICP-MS method provides low detection limits for all metals and has good reproducibility. However, it requires preliminary mineralization of blood samples using acids, which increases the analysis time and can lead to contamination of the samples under study [43]. Nevertheless, the ICP-MS method is optimal for elemental analysis of biological fluids, since, being multielement, it allows tracing the mutual influence of microelements and taking into account the synergism or antagonism of their action [44]. However, for single-element analysis, the direct atomic absorption highly selective method based on the use of Zeeman modulation polarization spectrometry (ZMPS) is more effective. The devices, the principles of which are based on the use of ZMPS, allow direct analysis of biological fluids, without preliminary decomposition of samples, which reduces the analysis time and avoids possible systematic errors associated with both the loss of heavy metal and sample contamination $[45,46]$.

Metals are known to be part of the structure of biological macromolecules, ensuring their normal functioning [47]. However, a number of metals (molybdenum, nickel, copper, chromium, cobalt, manganese and zinc), having an effect on living organisms, reveal mutagenic and carcinogenic activity [48]. In order to determine the mechanism of this negative impact of the specified number of metals on the human body, numerous studies of the effect of metals on the properties of nucleic acids have been carried out. The use of the spectroscopic method made it possible to study the interaction of DNA with chromium and potassium compounds. Infrared spectra of DNA films containing chromium sulfate, chromium chloride and potassium dichromate were obtained [49].

\section{Conclusion}

The study found that heavy metals have a negative impact on the natural environment, humans, animals and plants. As part of a review of the scientific literature on the subject of the work, analytical methods for determining the content of heavy metals in biological media were described. Nowadays, the development of affordable, easy-to-use and effective methods for the analysis of biomaterials is one of the most pressing problems in the field of study.

\section{References}

1. E.Yu. Shachneva, Scientific potential of regions for the service of modernization. AISI 2(3), 127-134 (2012)

2. E.S. Bukharinova, L.I. Toropov, XI All-Russian conference on the analysis of environmental objects with international participation "ECOANALITIKA-2019", 3536 (2019)

3. E.V. Khazhikhanova, Features of lesions of the nervous system in acute oral poisoning with thallium salts. Author's abstract of the thesis for the degree of Ph.D. in Medicine (SPb, 2006)

4. F. Al Hammouri, G. Darwazeh, A. Said, R.A. Ghosh, J. Med. Toxicol. 7(4), 306-11 (2011)

5. U.K. Misra, J. Kalita, R.K. Yadav, P. Ranjan, Postgrad Med. J. 79, 103-5 (2003)

6. R. Riyaz, S.L. Pandalai, M. Schwartz, Z.N. Kazzi, J. Med. Toxicol. 9(1), 75-80 (2013) 
7. T. Yumoto, K. Tsukahara, H. Naito et al., J. Clin. Diag. Res. 11(4), OD01-OD02 (2017)

8. E.A. Luzhnikov, G.N. Sukhodolova, Acute poisoning in adults and children: a guide to diagnosis and treatment (Eksmo, M., 2009)

9. A. Saddique, C.D. Peterson, Vet. Hum. Toxicol. 25, 16-22 (1983)

10. G.A. Gudzovsky, B.D. Minaev, F.T. Malykhin et al., Occupational Medicine 8, 32-36 (2004)

11. E.A. Drogichina, Occupational diseases of the nervous system (Medicine, M., 1968)

12. O.T. Zinina, Selected questions of forensic medicine and expert practice. Khabarovsk 4, 99-105 (2001)

13. A.I. Korbakova, N.S. Sorokin, N.N. Molodkina, etc., Occupational Medicine 5, 29-34 (2001)

14. A.P. Avtsyn, A.A. Zhavoronkov, M.A. Risch, L.C. Strochkova, Human microelementosis (Medicine, M., 1991)

15. A.V. Skalny, Human microelementosis (diagnosis and treatment): A practical guide for doctors and students of medical universities (Publishing house "Scientific world", M., 1999)

16. V.A. Kutyakov, An integrated approach to assessing the impact of lead and zinc compounds in forensic chemical research: Abstract of Ph.D. in Biology (Krasnoyarsk, 2016)

17. E.V. Agbalyan, Hygiene and sanitation 1, 14-16 (2012)

18. A.A. Mamyrbaev, L.D. Sakebaeva, U.A. Satybaldieva, G.E. Kuyanbaeva, Hygiene and sanitation 3, 25-29 (2012)

19. A.V. Eremeishvili, A.L. Firago, E.A. Bakaeva, Hygiene and sanitation 2, 20-23 (2012)

20. B.V. Zasorin, O.M. Kurmangaliev, L.S. Ermukhanova, Hygiene and sanitation 3, 1719 (2012)

21. M.S. Panin, Chemical ecology (Semipalatinsk, 2004)

22. E.G. Karpova, V.A. Archireeva, Hygiene and sanitation 6, 35-37 (1998)

23. I.V. Mikhailova, A.I. Smolyagin, V.M. Boev, Hygiene and sanitation 1, 63-65 (2012)

24. L.A. Chesnokova, I.V. Mikhailova, S.I. Krasikov, V.M. Boev, A.I. Smolyagin, Hygiene and sanitation 1, 65-69 (2012)

25. L.A. Bakulina, D.A. Shustov, Hygiene and sanitation 3, 49-52 (1990)

26. T.K. Larionova, Occupational Medicine and Industrial Ecology 4, 30-33 (2000)

27. E.E. Tekutskaya, L.I. Sofyina, L.V. Bender, N.P. Onishchenko, Hygiene and sanitation 3, 72-74 (1999)

28. B.V. Zasorin, O.M. Kurmangaliev, L.S. Ermukhanova, Hygiene and sanitation 3, 1719 (2012)

29. G.B. Slepchenko, N.P. Pikula, E.A. Zakharova et al., Hygiene and sanitation 3, 64-66 (2005)

30. S.X. Chen, C.L. Wiseman, D. Chakravartty, D.C. Cole, Int. J. Environ. Res. Public Health 8.14(3) (2017)

31. N. Singh, V.K. Gupta, A. Kumar, B. Sharma, Front Chem. 5, 70 (2017)

32. I.F. Seregina, S.Yu. Lanskaya, O.I. Okina, M.A. Bolshov, S.M. Lyapunov, O.L. Chugunova, A.S. Foktova, Journal of Analytical Chemistry 65(9), 986-994 (2010) 
33. I.D. Gadaskina, N.D. Gadaskina, V.A. Filov, Determination of industrial inorganic poisons in the body (L., 1975)

34. V.V. Kovalsky, A.D. Gololobov, Methods for the determination of trace elements in organs and tissues of animals, plants and soils (M., 1969)

35. B.V. Lvov, Atomic absorption spectral analysis (Nauka, Moscow, 1966)

36. J.C. Holmes, F.A. Morrell, Appl. Spectrosc. 11, 86-87 (1957)

37. G.S., Frysinger, R.B., Gaines, C.M. Reddy, Environ. Forensics 3, 27-34 (2002)

38. N.B. Ivanenko, N.D. Solovyev, A.A. Ivanenko, A.A. Ganeev, Arch. Environ. Contam. Toxicol. 63, 299-308 (2012)

39. F. Kummrow, F.F. Silva, R. Kuno, A.L. Souza, P.V. Oliveira, Talanta 75, 246-252 (2008)

40. N.I. Kaletina, Toxicological chemistry. Metabolism and analysis of toxicants (GEOTAR-Media, M., 2008)

41. N.D. Soloviev, N.B. Ivanenko, A.A. Ivanenko, V.A. Kashuro, Vestnik OSU 134(15), 127-130 (2011)

42. N.B. Ivanenko, A.A. Ganeev, N.D. Soloviev, L.N. Moskvin, Journal of Analytical Chemistry 66(9), 900-915 (2011)

43. E.V. Khazhikhanova, Features of lesions of the nervous system in acute oral poisoning with thallium salts. Author's abstract of the thesis for the degree of Ph.D. in Medicine ( $\mathrm{SPb}, 2006)$

44. N.B. Ivanenko, A.A. Ganeev, N.D. Soloviev, L.N. Moskvin, Journal of Analytical Chemistry 66(9), 900-915 (2011)

45. A.A. Ganeev, S.E. Sholupov, Spectrochim. Acta 50(B), 1227-1236 (1995)

46. F. Kummrow, F.F. Silva, R. Kuno, A.L. Souza, P.V. Oliveira, Talanta 75, 246-252 (2008)

47. A.A. Mamyrbaev, E.Zh. Bekmukhambetov, B.V. Zasorin, Hygiene and sanitation 3, 61-63 (2012)

48. N.V. Zaitseva, T.S. Ulanova, L.V. Plakhova, G.N. Suetina, Hygiene and Sanitation 4, 11-15 (2014)

49. V.M. Boev, V.F. Kuksanov, V.V. Bystrykh, Chemical carcinogens of the environment and malignant neoplasms (Medicine, M., 2002) 